ËESTI NSV TEADUSTE AKADEEMIA TOIMETISED: 22. KOIDË KEEMIA * GEOLOOGIA, 1973; NR, 4

ИЗВЕСТИЯ АКАДЕМИИ НАУК ЭСТОНСКОИ ССР. ТОМ 22

ХИМИЯ * ГЕОЛОГИЯ. 1973 , № 4

удК $551.794(261.24)$

ХЕЛЬГИ КЕССЕЛ, Н. ДАВЫДОВА, А. БЛАЖЧИШИН

\title{
ПЫЛЬЦА И ДИАТОМОВЫЕ ИЗ КОЛОНОК ГЛУБОКОВОДНЫХ ВПАДИН БАЛТИКИ
}

Для изучения истории Балтики большую ценность представляют материалы по стратиграфии ее донных отложений, особенно из глубоководных впадин. Нами изучено пять колонок этих отложений, взятых ударными и вибропоршневыми трубками с исследовательского судна «Профессор Добрынин» в диапазоне глубин от 41 до 314 м (см. рисунок). Полученные колонки после- и позднеледниковых отложений мощностью до 332 cм содержат сравнительно много древесных и травянистых пыльцы и спор хорошей сохранности. Во всех образцах отмечены Pediastrum boryanum и ее разновидности, Hystrichosphaeridae и Dinoflagellatae. Встречаемость зеленых водорослей в колонке из Эландской впадины $10-68 \%$ (по отношению к сумме пыльцы и спор, принятой за $100 \%$ ), содержание других микрофоссилий - незначительно. Попадаются также единичные, явно переотложенные зерна мезозойского и неогенового возраста, такие как пыльца липы, Leiotriletes, тип Trudopollis, тип Stellatoid, Podocarpus, Inarperturopollinites и др. Дочетвертичные пыльцевые зерна легко отличаются от четвертичных по коричневому цвету и уплощенной форме. При диатомовом анализе использована методика, разработанная в Институте океанологии АН СССР, которая дает возможность определить содержание диатомей в 1 г воздушно-сухого осадка, но с применением обогащения тяжелой жидкостью.

В А р конской в п адине в юго-западной части Балтики (рисунок, № 1465) с глубины $47 \mu$ взята колонка донных отложений следующего строения:

0-65 см - ил пелитовый темно-серый, начиная с 22 см - с серо-зелеными пятнами; 65-119 см - ил пелитовый серо-зеленый, с 80 cм - значительно плотнее и светлее, имеет резкую гранищу при переходе в следующий горизонт;

119-123 см - глина плотная, вязкая, голубовато-серая;

123-130 см - глина маслянистая, коричневато-серая, с резким нижним контактом;

130-157 см - алеврит ленточный серый с включениями гидротроилита, мощность глинистых лент до 0,5 см, алевритовых - до 1 см.

Из описания видно, что осадконакопление имело два хорошо выраженных в разрезе перерыва. Самая нижняя часть отложений в интервале 135-157 см характеризуется высоким содержанием пыльцы сосны и орешника. Она принадлежит к бореальному периоду, к зоне ВО, по системе Т. Нильссона (Nilsson, 1961). В составе древесных в интервале 105-135 см встречается большое количество пыльцы широколиственных пород (до $28 \%$ ), содержание пыльцы орешника достигает $40 \%$. По характеру пыльцы и диатомовых эти отложения относятся к атлантическому

5 ENSV TA Toimetised $\mathrm{K} * \mathrm{G}-41973$ 


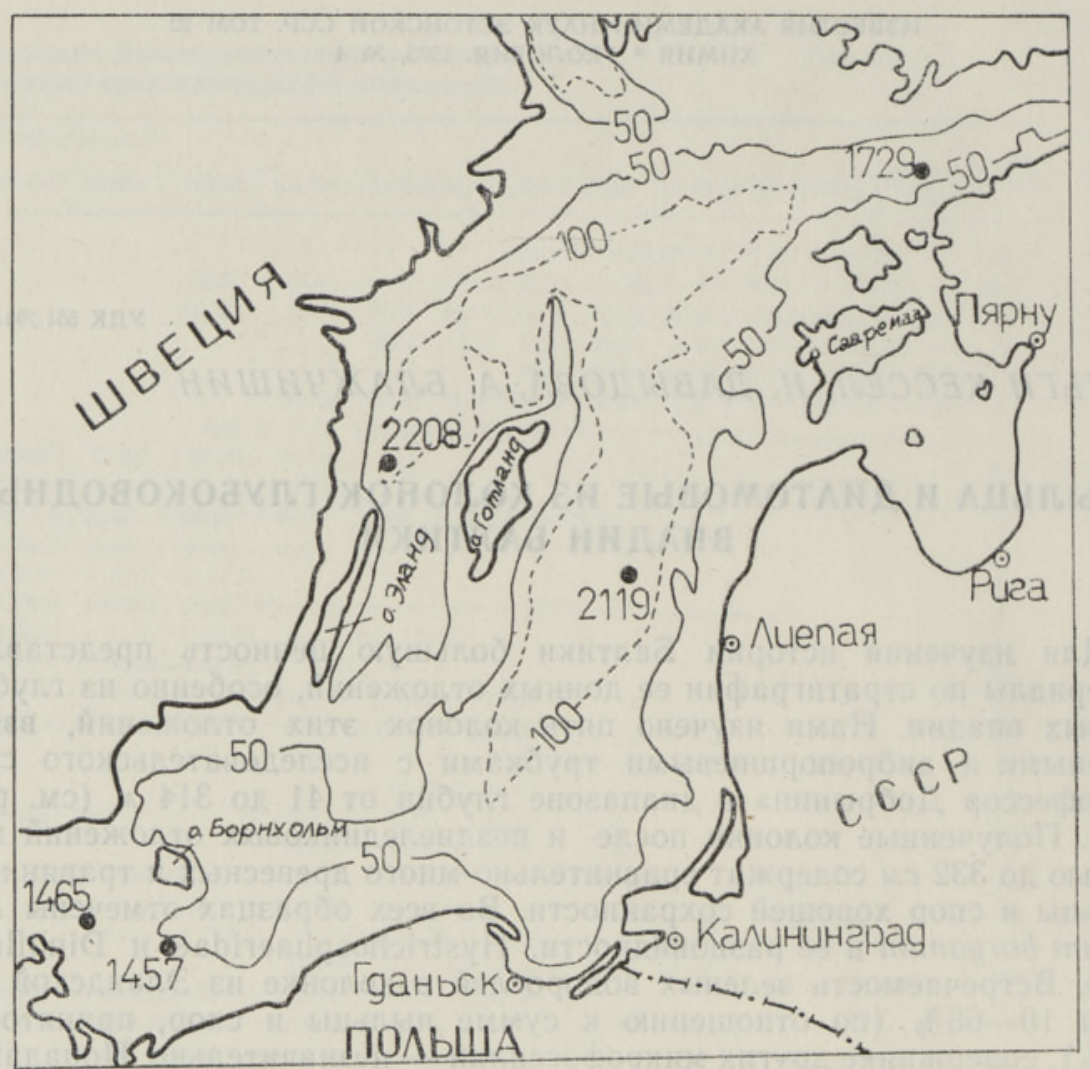

Батиметрическая схема центральной и южной частей Балтики (глубины в метрах).

(2) - местоположенне колонок глубоководных впадин.

периоду. Лежащая выше иловая толща принадлежит уже к суббореальному периоду (зона SB 2) вследствие меньшего содержания широколиственных пород. В самых верхних слоях разреза имеются пыльца и споры современной растительности.

В 8 образцах Арконской колонки найдено 48 таксонов диатомей. Содержание створок в 1 г осадка невелико - достигает 90 тыс., часто существенно меньше. В бореальных отложениях створки диатомей единичны - около 1000 в 1 г осадка. Встречены следующие морские планкгонные виды: Chaetoceros holsaticus, Dimerogramma minor, Melosira sulcata, Rhizosolenia hebetata, Thalassionema nitzschioides и пресноводные Stephanodiscus astraea var. minutulus и Diploneis smithii var. pumila. Вероятно эти отложения накопились в конце бореального периода, когда уже началось слабое осолонение Анцилового озера. Как известно, анциловый берег проходил в то время недалеко от юго-западного края Арконской впадины и существовало узкое сообщение через только что образовавшиеся проливы между Балтийским и Северным морями.

В атлантических отложениях в интервале $120-130$ см содержание диатомей возрастает до 5,6 тыс. на 1 г, видовой состав также более разнообразен. Преобладают морские диатомеи эу- и мезогалобы - на их долю приходится более $90 \%$ общего количества створок. Доминируют (около 1000 створок в 1 г осадка) Melosira sulcata и Thalassionema nitzschioides. Обильны (более 300 в 1 2) Cocconeis scutellum, Dimero- 
gramma minor, Rhizosolenia hebetata. Единично встречаются пресноводные диатомеи. Морские планктонные диатомеи составляют $60 \%$ всех створок. Значительное количество бентосных видов указывает на относительную близость берега. Характер диатомового комплекса свидетельствует, что соленость могла доходить до $10 \%$.

В суббореальных отложениях в интервале 20-105 cм количество створок диатомей колеблется от 27 до 91 тыс. на 1 г осадка, снижаясь до 1 тыс. в нижней части этих отложений. Доминируют (более 10 тыс. в 1 г) морские планктонные виды Melosira sulcata, Actinocyclus ehrenbergii и Rhizosolenia hebetata. Субдоминанты (более 5 тыс. в 1 г) Chaetoceros holsaticus, Dimerogramma minor. Обычны (более 2,5 тыс. в 1 2) Diploneis didyma, Plagiogramma staurophorum, Rhabdonema arcuatum, Synedra tabulata. Створки морских видов составляют в отложениях $94-99 \%$.

В субатлантических отложениях в интервале 0-20 cм содержание створок диатомей на 1 г осадка достигает 87 тыс. Доминируют (1626 тыс. в 1 2) Actinocyclus ehrenbergii и Melosira sulcata. Субдоминанты (более 5 тыс. в 1 2) - Chaetoceros holsaticus, Synedra tabulata и Rhizosolenia hebetata. Обычны (более 2,5 тыс. в 1 2) Dimerogramma minor, Diploneis didyma, Hyalodiscus scoticus.

Выделенные по палинологическим и диатомовым данным 4 части донных отложений Арконской впадины соответствуют анциловой (интервал 135-157 cм), литориновой $(105-135$ cм), лимниевой $(20-105$ см) и современной $(0-20$ cм) стадиям Балтики.

В колонке из юго-западной части Борнхольмской впадины (рисунок, № 1457) с глубины 41 м отложения представлены следующими разностями:

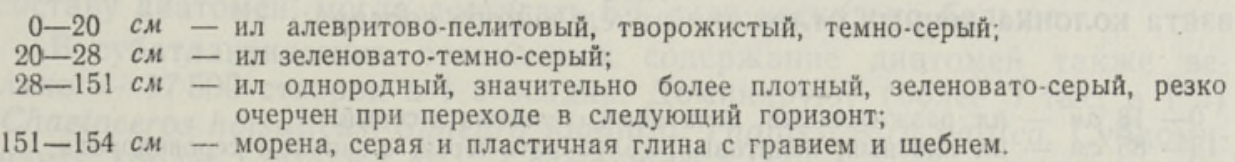

В морене пыльцевой анализ не производился. Спорово-пыльцевые спектры иловой толщи в интервале $60-151$ см характеризуются господством пыльцы древесных пород $(72-84 \%)$ при незначительном количестве пыльцы трав $(6-16 \%)$ и спор $(10-12 \%)$. В составе древесных встречаются пыльца сосны $(12-34 \%)$, березы $(21-31 \%)$ и ольхи $(15-30 \%)$. Из пыльцы широколиственных пород представлены дуб $(12-22 \%)$, вяз и липа (оба до $5 \%$ ). Содержание пыльцы орешника достигает $25 \%$, пыльцы граба и бука - $3 \%$, пыльцы ясеня - $2 \%$. Травы представлены в образцах с глубин 60-70 и 147-151 см пыльцой Gramineae $(30-45 \%)$, Cyperaceae $(2-21 \%)$, Chenopodiaceae $(1-14 \%)$, Rosaceae, Umbelliferae, Thalictrum $(6 \%)$, Ericaceae $(4 \%)$, Artemisia (9$12 \%$ ), Plantago (до 5\%), Filipendula (до 10\%). Пыльца других травянистых, а также клена, ивы содержится в количестве ниже $2 \%$ и спорадически. Споровые растения представлены в основном Bryales, Sphagnales, Polypodiaceae, Lycopodiales, среди которых господствуют зеленые мхи (до $70 \%$ от споровых). Толща ила в интервале 60-151 см по спорово-пыльцевым данным соответствует зоне SB 2, т. е. второй половине суббореала.

В самой верхней части ила содержание пыльцы низкое. В интервале 25-30 см отмечен субатлантический состав пыльцы: сосны $38 \%$, березы $26 \%$, ели $8 \%$, ольхи $16 \%$, широколиственных пород $12 \%$ (граба до $5 \%$, бука и клена до $2 \%$, ясеня $3 \%$ ). 
В суббореальных отложениях встречено 45 таксонов диатомей, в том числе 37 морских и 8 пресноводных видов. Доминируют (до 100 тыс. створок в 1 г осадка) морские планктонные виды Chaetoceros holsaticus и Melosira sulcata. Субдоминанты (до 20 тыс. в 1 2), также морские планктонные виды: Actinocyclus ehrenbergii, Dimerogramma minor, Thalassionema nitzschioides. Обычны (4-10 тыс. в 1 г) Chaetoceros affinis, Diploneis didyma, Grammatophora marina, Synedra tabulata и пресноводная Opephora martyi. Состав массовых и обычных форм показывает, что диатомовый комплекс сформировался в солоноводном бассейне с незначительным притоком пресных вод.

В субатлантических отложениях в интервале $0-60$ см доминируют те же диатомеи, что и в суббореальных, но с несколько пониженным содержанием (55-95 тыс. створок в 1 г осадка), а также Rhizosolenia hebetata (35 тыс. в 1 г). Субдоминанты (10-15 тыс. в 1 г) - Actinocyclus ehrenbergii, Diploneis didyma, Plagiogramma straurophorum и пресноводная Opephora martyi. Обильны (более 4 тыс. в 1 2) Chaetoceros mitra, Dimerogramma minor, Opephora marina, Synedra tabulata, Thalassionema nitzschioides. В целом диатомовый комплекс здесь беднее по составу, чем в суббореальном периоде. Встречено 22 таксона диатомей, в том числе 19 морских видов.

По палинологическим и диатомовым данным иловая толща Борнхольмской впадины подразделяется на две части, соответствующие лимниевой и современной стадиям Балтики.

Состав диатомей в послелиториновых отложениях Арконской и Борнхольмской впадин показывает, что в этот период соленость воды в разных юго-западных районах Балтики была одинаковой и близкой к современному значению, т. е. достигала $10 \%$.

В Эл анд ской в п а дин е (рисунок, № 2208) с глубины 138 и была взята колонка донных отложений следующего состава:

\footnotetext{
0- 18 см - ил разжнженный, пелитовый, зеленовато-серый;

18- $85 \mathrm{cм}$ - ил плотный, пелитовый, голубовато-серый с запахом сероводорода;

85-110 см - ил темно-серый с вкраплениями гидротроилита;

$110-250 \mathrm{cм}-$ глина плотная, голубовато-серая;

$250-332$ см - глина вязкая, плотная, желтовато-серая.
}

Глина в интервале 265-320 см характеризуется высоким содержанием пыльцы травянистых пород (до $40 \%$ ). Обнаружена пыльца Artemisia (до $50 \%$ всех травянистых пород). Среди пыльцы древесных пород доминирует пыльца сосны, но абсолютное преобладание ее (до 90\%) отмечается в нижней части глины. Второе место принадлежит пыльце березы $(9-20 \%)$, среди которой присутствуют Betula humilis и B. nana (до $18 \%$ всей пыльцы березы). Возраст глины - верхний дриас (зона DR 3).

Отложения в интервале 23-265 cм характеризуются невысоким содержанием травянистых пород (до 8\%). Состав древесных пород во всем интервале однородный: пыльцы сосны 50-84\% и березы 20-48\%. Данный интервал соответствует пребореальному периоду (зона РВ), самая же верхняя часть ила $(0-23$ см) относится к субатлантическому периоду (зона SA).

Отложения колонки Эландской впадины оказались бедны диатомеями: в 16 проанализированных образцах найдено всего 43 таксона. Количество створок в 1 г осадка редко превышает 1000, часто диатомеи единичны. В отложениях Балтийского приледникового озера в интервале 265-320 см встречаются единичные створки пресноводной Melosira islandica subsp. helvetica. 
Пребореальные отложения в интервале $23-265$ см также бедны диатомеями, что согласуется с данными (Блажчишин, Емельянова, 1971) о большом терригенном сносе в глубоководные впадины в позднеледниковый и пребореальный периоды. Количество створок в этих отложениях колеблется от единиц до нескольких сотен и только в интервале $40-70 \mathrm{~cm}$ возрастает до нескольких тысяч экземпляров. Доминируют (более 1000 створок в 1 г осадка) планктонные виды мезогалобы: Chaetoceros holsaticus, Coscinodiscus lacustris var. septentrionalis, Synedra tabulata, Thalassiosira baltica. Обычны $(200-600$ в 1 2) также мезогалобы Actinocyclus ehrenbergii, Grammatophora oceanica, Rhizosolenia hebetata, Cocconeis scutellum. По всей толще в небольшом количестве встречаются пресноводные диатомеи, обитатели крупных глубоких холодноводных озер: Melosira islandica subsp. helvetica, $M$. distans var. alpigena, $M$. italica subsp. subarctica, Stephanodiscus astraea var. minutulus, S. niagarae. Всего в пребореальных отложениях найдено 35 таксонов диатомей, в том числе 16 морских видов (эу-и мезогалобы), 4 галофила, 13 индиферентов и 2 галофоба. Солоноводный характер диатомового комплекса Иольдиевого моря еще более очевиден при подсчете суммарного количества створок диатомей по экологическим группам: эу- и мезогалобы составляют $70 \%$ общего количества створок, галофилы - $4 \%$, а индиференты и галофобы - $26 \%$. Такой состав диатомового комплекса обусловлен тем, что колонка взята в непосредственной близости от древнего средне-шведского пролива, соединявшего в пребореале балтийскую котловину с мировым океаном. Поступавшие через пролив придонные воды осолоняли близлежащие районы Иольдиевого моря и несли с собой морские диатомеи. Соленость эландской впадины и прилегающих к ней более мелководных участков была наибольшей в Иольдиевом море и, судя по составу диатомей, могла достигать $5 \%$ или несколько больше.

В субатлантических отложениях содержание диатомей также велико - 17500 створок в 1 г осадка. Доминируют (более 3 тыс. в 1 г) Chaetoceros holsaticus, Synedra tabulata, Thalassiosira baltica. Субдоминанты (более 1 тыс. в 1 г) - Coscinodiscus lacustris var. septentrionalis, Actinocyclus ehrenbergii. Обычны (более 500 в 1 2) Achnanthes taeniata и пресноводный галофил Epithemia turgida. В число массовых и обычных входят преимущественно солоноводные виды мезогалобы. Диатомовый комплекс субатлантических отложений существенно отличен от более солоноводного по характеру диатомового комплекса из юго-западных впадин Балтики, что вполне закономерно и соответствует низкой солености воды в районе Эландской впадины.

Выделенные по палинологическим и диатомовым данным 3 части донных отложений Эландской впадины соответствуют Балтийскому приледниковому озеру (интервал 265-320 cм), иольдиевой $(23-265$ см) и лимниевой $(0-23$ см) стадиям Балтики.

В Восточно-Готландской впадине (рисунок, № 2119) с глубины $173 м$ взята колонка донных отложений следующего состава:

0 - 30 см - ил творожистый, пелитовый, зеленовато-серый;

30- 64 см - ил слабо полосчатый с растительными остатками на глубине $40-45$ см;

64-102 см - ил полосчатый с растительными остатками на глубине $85-90$ см;

102-128 см - глина серая с черными примазками;

128-180 см - глина пепельно-серая, мраморовидная с ярко-черными гидротроилитовыми примазками и прослойками гидротроилита на глубине $134-140$ см и гравия на глубине $144-147$ см;

$180-200$ см - глнна плотная с примазками;

200-247 cм - глина плотная без примазок. 
Глина в интервале 200-247 см характеризуется высоким содержанием пыльцы травянистых растений $(42-44 \%)$, содержание пыльцы древесных пород - $38 \%$ и спор - $18-20 \%$. В составе пыльцы травянистых растений обнаружены Artemisia (51-63\%), Chenopodiaceae (12-13\%), Gramineae и Cyperaceae (соответственно ниже и выше 10\%). Среди пыльцы древесных пород доминирует пыльца сосны (46-57\%). Далее следует пыльца березы $(40-50 \%)$, в составе которой присутствуют Betula humilis и B. nana $(40-50 \%)$. Возраст глины - верхний дриас (зона DR 3)

В отложениях из интервала $50-200$ см среди пыльцы древесных по род встречаются пыльца сосны $(31-46 \%)$, березы $(15-30 \%)$ и ольхи $(10-29 \%)$. Содержание пыльцы широколиственных пород на глубине 185 cм достигает $26 \%$ (дуба - $15 \%$, липы $8 \%$ и вяза $3 \%$ ), пыльцы ели $5 \%$ и орешника - $50 \%$. Возраст данных отложений, по всей вероятности, атлантический.

Для иловой толщи в интервале 20-50 см характерно пониженное содержание пыльцы широколиственных пород и орешника (зона SB). Самая верхняя часть колонки в интервале 15-20 см принадлежит к субатлантическому периоду (зона SA).

Содержание диатомей в отложениях очень незначительно. Из 27 просмотренных образцов 12 оказались немыми. В отложениях верхнего дриаса встречены единичные осколки створок Actinocyclus ehrenbergii и Opephora martyi. Возможно, что они переотложены.

В отложениях атлантического времени, диатомеи распределены крайне неравномерно: в одних образцах они полностью отсутствуют, в других их содержание не превышает 1 тыс., а в некоторых достигает 25 и даже 93 тыс. створок на 1 г осадка. Экологический состав диатомей также неоднороден. В нижней части отложений (150-200 cм) вскрыта богатая морская флора, где диатомеи эу- и мезогалобы составляют 70-98\% общего количества створок. Из 26 встреченных таксонов 16 мезогалобов, 5 эугалобов и 5 пресноводных видов. Доминируют $(30-35$ тыс. створок в 1 г осадка) морские эугалобы: Chaetoceros holsaticus, Melosira sulcata. Обычны (2,5-8 тыс. в 1 2) Actinocyclus ehrenbergii, Dimerogramma minor, Thalassionema nitzschioides. В заметных количествах присутствуют пресноводные Melosira islandica subsp. helvetica, Opephora martyi.

Выше по разрезу содержание диатомовых незначительно. Осадконакопление, по-видимому, осложнялось интенсивными процессами размыва и переотложения, о чем свидетельствуют песчаные прослойки, органические остатки, а также относительно более высокое содержание пресноводных водорослей, по-видимому, в значительной степени переотложенных из анциловых отложений. В верхней части атлантических отложений доминируют (более 3 тыс. створок в 1 г осадка) морские виды Actinocyclus ehrenbergii, Chaetoceros holsaticus, C. mitra, Rhizosolenia hebetata и пресноводная Melosira islandica subsp. helvetica. Субдоминанты (более 1 тыс. в 1 2) - Chaetoceros subsecundus, Thalassionema nitzschioides и пресноводный Stephanodiscus astraea с вариететами.

В суббореальных отложениях из интервала 20-50 см максимальное содержание диатомей превышает 100 тыс. створок в 1 г осадка. Доминируют (более 20 тыс. в 1 г) морские планктонные диатомеи: Actinocyclus ehrenbergii, Rhizosolenia hebetata. Субдоминант (14 тыс. в 1 г) Chaetoceros holsaticus, Обычны (5-8 тыс. в 1 2) Chaetoceros affinis, C. curvisetus, Coscinodiscus lacustris var. septentrionalis, Thalassionema nitzschioides и Melosira islandica subsp. helvetica.

Состав массовых видов и общий характер диатомового комплекса указывают на образование отложений в условиях открытого моря с со- 
леностью, близкой к современной в этом районе, а также на принос пресноводных диатомей.

В субатлантических отложениях содержание диатомей ниже, чем в суббореальных, и достигает 23,6 тыс. створок в 1 г осадка. Доминирует (10 тыс. и более створок в 1 г осадка) Rhizosolenia hebetata. Субдоминанты (4 тыс. в 1 г) - Actinocuclus ehrenbergii, Chaetoceros holsaticus. Стводок пресноволных диатомей, главным образом Melosira islandica subsn. helvetica и Stephonodiscus astraea. в субатлантических отложениях до $7 \%$ обшего содепжания диатомей. что свидетельствует о сходстве процессов селименташии, разноса диатомей и формирования диатомовых комплексов на ппотяжении позднего голоцена.

По палинологическим и диатомовым данным в донных отложениях Весточно-Готлантской впалины. по всей вепоятности. вытетяются птложения Балтийскпго ппилетникорого озепа (интепвал 200-247 cм), Литоринпвпто $(50-200$ см) и Лимниевого (0-50 см) морей.

В Финском заливе к югу от п - в а Х ан ка (рислнок, № 1729) на глубине 132 м взта колонка донных отложений следующего состава:

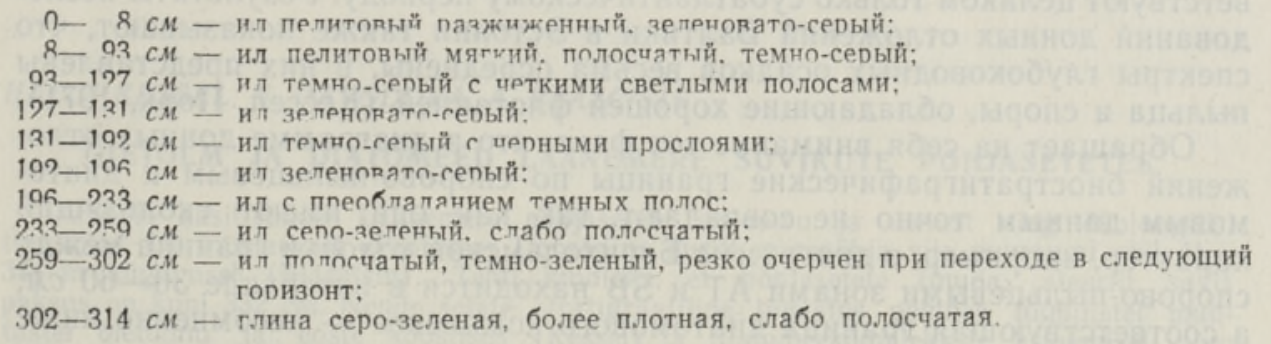

Спопово-пыльшевые спектры колонки в интервале $0-314$ см хапактеризуются госполством пыльшы сосны (ло $80 \%)$. а в интепвале $150-210 \mathrm{~cm}-$ полтемом кпивой пыльшы ели (ло $21 \%$ ). В большинстве случаев солержание пыльшы ольхи не более $10 \%$. пыльца березы колеблется в ппеделах $10-33 \%$. Пыльша шипоколиственных пород наблюлаетгя в небольшом количестве: дуба и вяза - оба до $5 \%$, липы до $3 \%$. Невелико содепжание пыльцы орешника (до $6 \%$ ). Обший состав пылышы и спор по разпезу одноподен: пыльца древесных пород составляет $72-90 \%$, травянистых $4-10 \%$ и споровых до $20 \%$, что позволяет отнести эти отложения к пепвой (интервал 100-314 см) и второй половине $(0-100$ см) субатлантического периода.

В проанализированных 15 образцах содержится обильная диатомовая флора - 99 видов и разновилностей. В 1 г осадка насчитывается от нескольких сот до более чем 100 тыс. створок, что очень значительно для более молодых отложений Балтики. Преобладают мопские виды (эу- и мезогалобы), составляющие $60 \%$ таксонов и от 64 до $90 \%$ общего содержания створок в отложениях.

Доминируют (более 10 тыс. в 1 2) морские солоноводные виды Achnanthes taeniata, Actinocyclus ehrenbergii, Coscinodiscus lacustris var. septentrionalis, Synedra tabulata и пресноводная галофильная Epithemia turgida. Субдоминанты (более 1 тыс. в 1 2) представлены морскими видами Chaetoceros holsaticus, Diploneis didyma, Grammatophora marina, G. oceanica, Thalassiosira baltica и пресноводными галофилами Cocconeis pediculus, Rhoicosphaenia curvata. В меньших количествах, но постоянно в отложениях встречаются морские виды Biddulphia levis, Coscinodiscus commutatus, Hyalodiscus scoticus, Rhizosolenia hebetata, 
Thalassiosira nana, а из пресноводных индеферентов-Melosira islandica subsp. helvetica и Rhopalodia gibba.

Диатомовый комплекс формировался в условиях сильно опресненного моря в непосредственной близости от побережий, куда приносились как диатомеи морских мелководий, так и пресноводные, выносимые реками диатомен.

По палинологическим и диатомовым данным донные отложения Финского залива к югу от п-ва Ханка накоплялись только в лимниевой стадии.

Приведенный нами материал о колонках донных отложений из глубоководных впадин Балтики показывает, что изученные отложения можно уверенно подразделять на голоценовый и верхнеплейстоценовый горизонты. Ни в одной колонке донных отложений все голоценовые зоны целиком не представлены, так как осаждение в глубоководных впадинах также испытывало перерывы. Имеющиеся данные, правда немногочисленные, позволяют предположить, что глубоководные колонки характеризуются почти одинаковым спорово-пыльцевым составом. Например, отложения колонки, взятой в Финском заливе к югу от п-ва Ханка, соответствуют целиком только субатлантическому периоду. Результаты исследований донных отложений Балтики в Эстонии также показывают, что спектры глубоководных осадков весьма осреднены, в них представлены пыльца и споры, обладающие хорошей флотацией (Кессел, Порк, 1971).

Обращает на себя внимание тот факт, что в диаграмме донных отложений биостратиграфические границы по спорово-пыльцевым и диатомовым данным точно не совпадают, так как они имеют скользящий характер, например, в диаграмме Борнхольмской колонки граница между спорово-пыльцевыми зонами АТ и SB находится в интервале $30-60$ см, а соответствующая граница диатомового комплекса - несомненно ниже его.

Выполненные палинологические исследовання донных отложений показывают, что разным этапам развития растительности в голоцене и позднем плейстоцене соответствуют определенные геоботанические районы Прибалтики. Поэтому при интерпретации материалов из Арконской и Эландской впадин использовано подразделение спорово-пыльцевых зон, разработанное для Южной Швеции (Nilsson, 1961, 1964; Berg. lund, 1966) и для о. Рюген (Kliewe, Lange, 1968). При определении дочетвертичных микрофоссилий использованы материалы У. Миллер (Miller, 1971). При интерпретации спорово-пыльцевой диаграммы Финского залива за основу взяты материалы по Северо-Западной Эстонии (Кессел, Порк, 1971).

Исследования диатомей в 5 колонках донных отложений из глубоководных впадин Балтики позволяют достаточно полно охарактеризовать диатомовые комплексы в субатлантических отложениях глубоководных районов, а также выделить диатомовый комплекс пребореального Иольдиевого моря в Эландской впадине, сформировавшийся в непосредственной близости от древнего пролива, соединявшего балтийскую котловину с мировым океаном.

К сожалению, вскрытые отложения неполны, особенно в отношении атлантического периода, что затрудняет датировку отдельных горизонтов, соответствующих Литориновому и Лимниевому морям. Можно надеяться, что в ближайшее время будут заложены новые колонки, которые дадут более полное представление о стратиграфии и экологии разновозрастных бассейнов Балтики. 


\section{ЛИТЕРАТ У РА}

Блаж чишин А. И., Е мельянов а Е. М., 1969. Геологические исследования в Балтийском море на и/с «Профессор Добрынин», Океанология, 9, № 6.

К ессел Х. Я., Порк М. И., 1971. К стратиграфии донных отложений Балтики в пределах Эстонии. В сб.: Палинологические исследования в Прибалтике. Рига.

Berglund B. E. 1966. Late-Quaternary vegetation in eastern Blekinge, southeastern Sweden. A pollen-analytical study. II Post-Glacial time. Opera Botanica, 12, Nr. 2.

K l i ewe H., Lange E. 1968. Ergebnisse geomorphologischer, stratigraphischer und vegetationsgeschichtlicher Untersuchungen zur Spät- und Postglazialzeit auf Rügen. Peterm. Geogr. Mitt., 112 Jg., H. 4.

Miller U. 1971. Microfossils in the Quaternary layers at Tofthög, southern Scania. Geol. Fören. Stockh. Förh., 93, No. 546.

$\mathrm{N}$ ils s o n T. 1961. Ein neues Standardpollendiagramm aus Bjärsjöholmssjön in Schonen. Lunds Univ, Årsskr., N. F., Avd. 2, 56.

$\mathrm{Nils}$ s on T. 1964. Standardpollendiagramme und $\mathrm{C}^{14}$-Datierungen aus dem Ageröds mosse im mittleren Schonen. Lunds Univ. Årsskr., N. F., Avd. 2, 59, Nr. 7.

Ннститут геологии

Академии наук Эстонской ССР
Поступила в редакцию

13/III 1973

\section{HELGI KESSEL, N. DAVODOVA, A. BLAZCISIN}

\section{OIETOLM JA DIATOMEED LAÄNEMERE SUVIKUTE POHJASETETES}

Artiklis käsitletakse Läänemere pōhjasetete iseloomu ja vanust ning ökoloogilisi tingimusi. Uurimislaevalt «Professor Dobrōnin» uuriti merepōhja viie puuraugu abil 41 $314 \mathrm{~m}$ sügavusel (Blažčišin). Tehti kindlaks, et pōhjasetete (muda, aleuriit, savi) paksus on kuni $332 \mathrm{~cm}$. Nende setete stratigraafiline liigestus põhineb tüüpilistel muutustel õietolmu ja eoste koostises (Kessel) ja diatomeekomplekside esinemisel ning iseloomul (Davōdova).

Selgus, et settimine algas Arkona nõos boreaalis, Bornholmi nõos subboreaalis, Olandi ja Gotlandi nöos nooremas drüüases ja Hango saare lähedal Soome lahes subatlantilise aja esimesel poolel ning on jätkunud nüüdisajani. Oheski puursüdamikus ei ole esindatud kogu hilisglatsiaali vōi holotseeni setteid tervikuna, kuna settimine on isegi sügavamaveelistes nōgudes toimunud lünklikult.

Oietolmu analüüsi ja diatomeefloora rikkaliku ja mitmekesise koostise abil tehti kindlaks, et Balti paisjärve mageveelisi setteid esineb Olandi ja Gotlandi nōos, Joldiamere riimveelisi setteid Olandi nōos, Litoriinamere riimveelisi setteid Arkona ja Gotlandi nōos ja Limneamere riimveelisi setteid Arkona, Bornholmi, Olandi, Gotlandi nōos ning Soome lahes Hango saare lähedal.

Läänemere pöhjasetete õietolmu ja eoste spektrid on küllaltki ebaselged, kuna need setted on flotatsiooni tagajärjel osaliselt segunenud.

\section{HELGI KESSEL, N. DAVYDOVA, A. BLAZHTSHISHIN}

\section{POLLEN AND DIATOMS IN THE BORING CORES OF BOTTOM SEDIMENTS IN THE DEPRESSIONS OF THE BALTIC SEA}

The character, age and ecological conditions of the bottom deposits of the Baltic Sae are described. During the R/V "Professor Dobrynin" expedition 5 boreholes were made at depths of $41-314 \mathrm{~m}$ (Blazhtshishin). The thickness of the bottom sediments (silty mud, silt, clay) amounts up to $332 \mathrm{~cm}$. The stratigraphical subdivision of these sediments is based on the typical changes in the pollen and spore composition (Kessel) and on the occurrence and character of diatomic complexes (Davydova).

In the studied depressions, sedimentation began in the following climatic periods: in Arkona - in the Boreal Age; in Bornholm - in the Subboreal Age; in Oland and Gotland - in the Younger Dryas Age, and near the Hango Island in the Finnish Gulf in the early part of the Subatlantic. The sedimentation continues up to the present. None of the bore holes represents the whole cycle of all Late-Glacial and Holocene zones, for in the deep-water depressions sedimentation took place with a hiatus. 
According to the pollen-analytical data and to the abundant and various composition of diatom flora, the following sediments have been stated: the fresh-water sediments of the Baltic Ice Lake (depressions of Oland and Gotland); the brackish-water sediments of the Yoldia Sea (d. of Oland); the brackish-water sediments of the Litorina Sea (d. of Arkona and Gotland); the brackish-water sediments of the Limnea Sea (d. of Arkona, Bornholm, Oland, Gotland and the Finnish Gulf).

The results of the investigations of the bottom sediments of the Baltic Sea show that the pollen and spores spectra of these sediments are unclear because the bottom sediments have been mixed by flotations. 